\title{
Hepatoprotective Effect of Captopril on Liver Toxicity Induced by High and Low Dose of Paracetamol in Rats: Histological Study
}

\author{
Turki M. Al-Shaikh', Mahmoud M. E. Mudawi ${ }^{2 *}$, Abdelhadi Y. A. Yassin², Rami S. Habeballa ${ }^{2}$ and \\ Vijay R. Chidrawar ${ }^{2}$ \\ 'Department of Biological Sciences, Faculty of Science, Northern Border University, Arar, Saudi Arabia \\ 2Department of Pharmacology and Toxicology, Faculty of Pharmacy Northern Border University, Saudi Arabia; \\ mmudawi@hotmail.com
}

\begin{abstract}
Many patients may administered medications like captopril (ACE inhibitor) for treatment of chronic diseases and may also take Paracetamol as an Over The Counter (OTC) drug which may interact with captopril. Therefore, the aim of this study is to evaluate of the hepatoprotective effect of captopril on liver toxicity induced by low and high dose of paracetamol in rats. This study was conducted in two phases: first study for low dose of paracetamol (300 mg/kg); animals were divided into 4 groups of 6 rats each $(\mathrm{n}=6)$; all groups were treated orally either $0.9 \%$ Normal Saline (NS), captopril $20 \mathrm{mg} / \mathrm{kg}$, paracetamol $300 \mathrm{mg} / \mathrm{kg}$ or captopril $20 \mathrm{mg} / \mathrm{kg}$ plus paracetamol $300 \mathrm{mg} / \mathrm{kg}$ for 10 consecutive days. Second study for single high dose of paracetamol (3000 mg/kg); animals were divided into 4 groups of 6 rats each $(\mathrm{n}=6)$; all groups were pretreated orally either $0.9 \%$ Normal Saline (NS) or captopril $20 \mathrm{mg} / \mathrm{kg}$ for 7 consecutive days followed by single oral administration of Paracetamol $3000 \mathrm{mg} / \mathrm{kg}$ or normal saline. The administration of Paracetamol or normal saline was performed 24 hours after the last administration of captopril. After 48 hours of hepatic injury induction, the animals were then sacrificed and the liver was removed for histopathological studies. Low dose $(300 \mathrm{mg} / \mathrm{kg})$ for 10 days and high single dose $(3000 \mathrm{mg} / \mathrm{kg})$ of paracetamol produced hepatotoxic effects. While captopril $20 \mathrm{mg} / \mathrm{kg}$ showed marked protection against changes induced by low and high dose of paracetamol on the liver.
\end{abstract}

Keywords: Acetaminophen, Captopril, Hepatoprotective, Hepatotoxicity, Paracetamol

\section{Introduction}

\subsection{Paracetamol Toxicity}

Paracetamol (acetaminophen) is one of the most commonly used analgesic and antipyretic drugs ${ }^{1}$. It is a rapid, reversible, noncompetitive inhibitor of cyclooxygenase activity $^{2}$. Paracetamol is widely used over the counter pain and fever reliever, and remains a major cause of overdose and overdose-related Acute Liver Failure (ALF) and death in the United States, united kingdom and many other countries like Saudi Arabia ${ }^{3,4}$.
The World Health Organization estimates that total number of acute unintentional poisonings throughout the world ranges from 3.5-5.0 million cases annually, of which 3 million are severe poisonings resulting in 20000 deaths annually ${ }^{5,6}$. On the other hand, lack of knowledge of patients on Over The Counter (OTC) drugs lead to irrational use $\mathrm{e}^{7}$.

Acetaminophen has long been recognized as potentially lethal because of dose-related hepatotoxicity and often nephrotoxicity ${ }^{2,8}$. It is reported that paracetamol can cause acute and chronic nephrotoxic effects?.

* Author for correspondence 
Acute toxicity after ingestion of large doses (10-15 g) is characterized by necrosis and damage to the proximal tubule. Chronic ingestion of much lower doses (500-1000 $\mathrm{mg}$ ) can produce renal damage ${ }^{9}$.

\subsection{Captopril}

Angiotensin Converting Enzyme inhibitors (ACE inhibitors) like captopril is widely used for treatment of hypertension and congestive heart failure ${ }^{10}$. They are used for long-term management of patients with congestive heart failure, as well as diabetic and non-diabetic nephropathies ${ }^{11}$.

Captopril contains active sulfhydryl group and shares other structural feature with cysteine which is the main substrate for glutathione ${ }^{10}$. According to a study published in the year 2000 the result showed that captopril was able to enhance total glutathione content as well as glutathione peroxidase and glutathione reductase activities in various mouse tissues. While another study published in the year 2008 showed that captopril decreased the activity of both glutathione peroxidase and glutathione reductase ${ }^{13}$. However, Single doses of captopril given to rats produced a significant time dependent depletion of hepatic glutathione ${ }^{10}$.

\section{Background of the Study}

Many patients may administered medications like captopril (ACE inhibitor) for treatment of chronic diseases and may also take Paracetamol as an Over The Counter (OTC) drug which may interact with captopril. Therefore, the aim of this study is to evaluate of the effects of captopril, low and high dose of Paracetamol on the liver of rats.

\section{Materials and Methods}

\subsection{Materials}

\subsubsection{Animals}

Wistar rats weighing 200-250 g were used in this study. The animals were kept and maintained under laboratory conditions in the Faculty of Pharmacy, Northern Border University, KSA; and were allowed free access to food (standard pellet diet) and water ad libitum. The animals were divided into 8 groups of 6 animals.

\subsubsection{Drugs}

Captopril (Capoten $)$ and Paracetamol (Panadol ${ }^{\circ}$ ) were purchased from the local market in KSA.

\subsection{Methods}

\subsubsection{Experimental Protocol}

\subsubsection{Low Dose Paracetamol (300 mg/kg)}

Animals were divided into 4 groups of 6 rats each $(\mathrm{n}=$ 6). All groups were treated orally either $0.9 \%$ Normal Saline (NS), captopril $20 \mathrm{mg} / \mathrm{kg}$, Paracetamol $300 \mathrm{mg} / \mathrm{kg}$ or captopril $20 \mathrm{mg} / \mathrm{kg}$ + paracetamol $300 \mathrm{mg} / \mathrm{kg}$ for 10 consecutive days. The animals were then sacrificed and the liver was removed for histopathological studies.

Table 1. Animal grouping and treatment schedule

\begin{tabular}{ll}
\hline Group & Treatment \\
\hline Group 1 & Normal control group received normal saline \\
Group 2 & Paracetamol control group $300 \mathrm{mg} / \mathrm{kg}$ \\
Group 3 & Captopril $20 \mathrm{mg} / \mathrm{kg}$ \\
Group 4 & Captopril $20 \mathrm{mg} / \mathrm{kg}+$ Paracetamol $300 \mathrm{mg} / \mathrm{kg}$ \\
\hline
\end{tabular}

\subsubsection{High Dose Paracetamol (3000 mg/kg)}

Animals were divided into 4 groups of 6 rats each $(\mathrm{n}=$ 6). All groups were pretreated orally either $0.9 \%$ Normal Saline (NS) or captopril $20 \mathrm{mg} / \mathrm{kg}$ for 7 consecutive days followed by single oral administration of Paracetamol $3000 \mathrm{mg} / \mathrm{kg}$ or normal saline. The administration of Paracetamol or normal saline was performed 24 hours after the last administration of captopril. After 48 hours of hepatic injury induction, the animals were then sacrificed and the liver was removed for histopathological studies $^{14,15}$

Table 2. Animal grouping and treatment schedule

\begin{tabular}{ll}
\hline Group & Treatment \\
\hline Group 1 & Normal control group received normal saline \\
Group 2 & Paracetamol control group 3000mg $/ \mathrm{kg}$ \\
Group 3 & Captopril $20 \mathrm{mg} / \mathrm{kg}$ \\
Group 4 & Captopril $20 \mathrm{mg} / \mathrm{kg}+$ Paracetamol 3000 $\mathrm{mg} / \mathrm{kg}$ \\
\hline
\end{tabular}

\subsubsection{Histological Study}

The liver tissue was dissected out and fixed in 10\% formalin. The tissues were processed and embedded in paraffin wax and sectioned. Sections were stained with Haematoxylin and Eosin (H\&E) dye for microscopic observation of histological changes in the liver ${ }^{14,15}$. 


\section{Results}

\subsection{Histological Findings of the Liver (Low Dose Paracetamol and Captopril)}

As shown in the figures; sections from rat liver stained by $\mathrm{H} \& \mathrm{E}$ demonstrated that the liver sections from normal control group treated with normal saline at Central Vein region (CV) hepatocytes showed lightly stained cytoplasm with rounded central euchromatic nuclei (thin black arrows). Cell plates are separated by thin wall blood sinusoids lined by flat endothelial cells (white arrows) (Figure 1). While the histopathological examination of the liver tissue of rats pre-treated with paracetamol $300 \mathrm{mg} / \mathrm{kg}$ for 10 days showed marked congestion of Central Vein (CV). Hepatocytes (black dotted arrows) have darker cytoplasm, increased bi nucleation or dark enlarged nuclei (karyomegaly). In the second animal the cells looked shrunken and separated from each other or lost their outlines. Blood sinusoids are congested in some samples and Von Kupffer cell nuclei are more numerous and prominent (white arrows). Fibrous tissue proliferation could be seen around the veins and may be extend between lobules (stars) (Figure 2).

Liver sections from rats pre-treated with captopril $20 \mathrm{mg} / \mathrm{kg}$ for 10 days demonstrated that the hepatocytes have more active euchromatic nuclei compared to control (black arrows). Sinusoids are infiltrated by mononuclear cells (white arrows) (Figure 3).

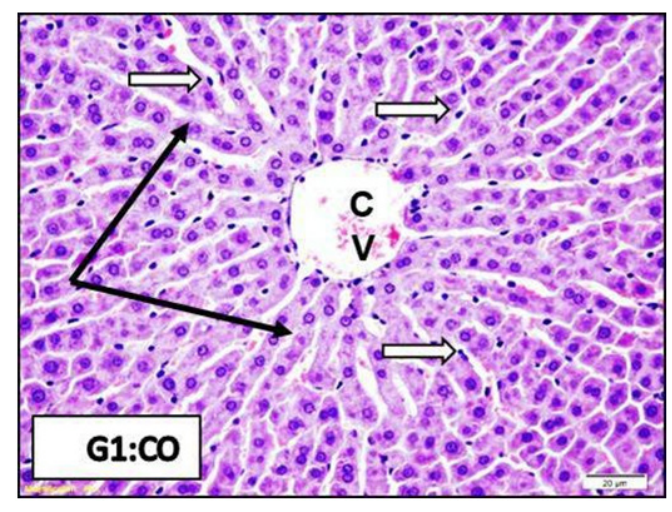

Figure 1. Normal control group: sections from rat liver stained by H\&E.

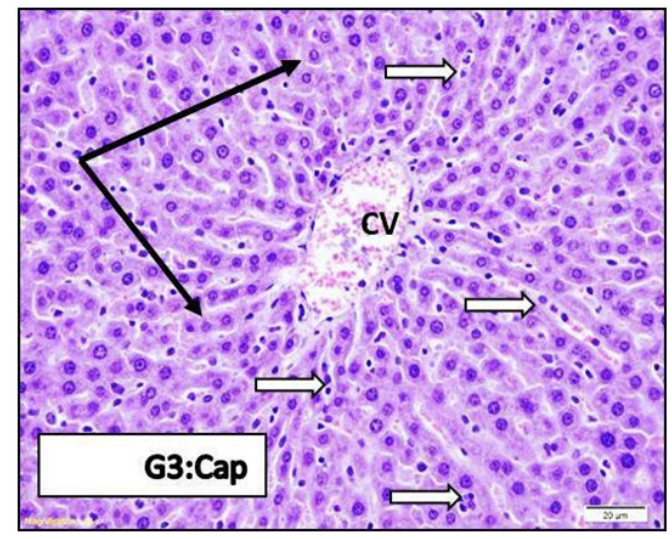

Figure 3. Captopril $20 \mathrm{mg} / \mathrm{kg}$ group: sections from rat liver stained by H\&E.

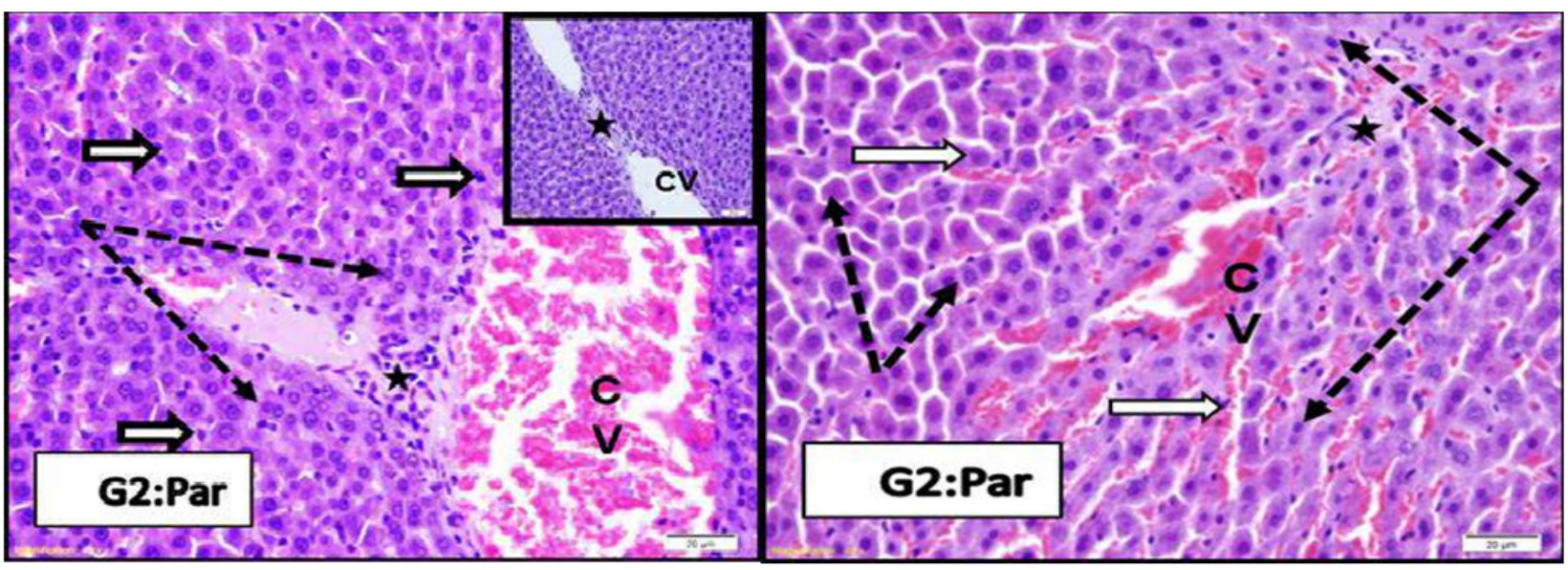

Figure 2. Paracetamol $300 \mathrm{mg} / \mathrm{kg}$ group: sections from rat liver stained by H\&E. 
Interestingly, the liver sections from rats pre-treated with captopril $20 \mathrm{mg} / \mathrm{kg}$ and paracetamol $300 \mathrm{mg} / \mathrm{kg}$ concomitantly for 10 days showed marked protection against changes induced by paracetamol. Hepatocytes (arrows) looked normal with active euchromatic nuclei similar or healthier than control. No congestion of blood vessels or sinusoids (white arrows) (Figure 4).

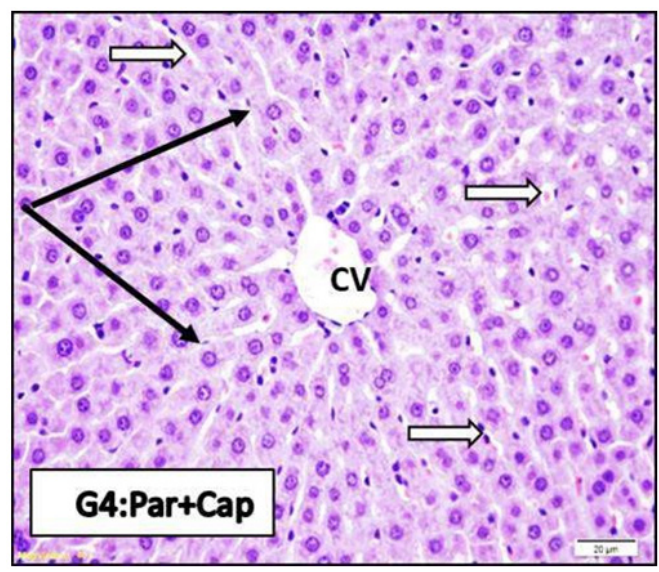

Figure 4. Captopril $20 \mathrm{mg} / \mathrm{kg}+$ Paracetamol $300 \mathrm{mg} /$ kg group: sections from rat liver stained by $H \& E$.

The figures shown in sections from rat liver at the portal region were branches of Bile Ducts (BD) and Portal Veins (PV) could be seen. Sections from normal control group treated with normal saline (G1) showed normal portal contents and nearby hepatocytes (arrows) (Figure 5). The histopathological examination of the liver tissue of rats pre-treated with paracetamol $300 \mathrm{mg} / \mathrm{kg}$ for 10 days (G2) showed shrunken hepatocyte cell cords with

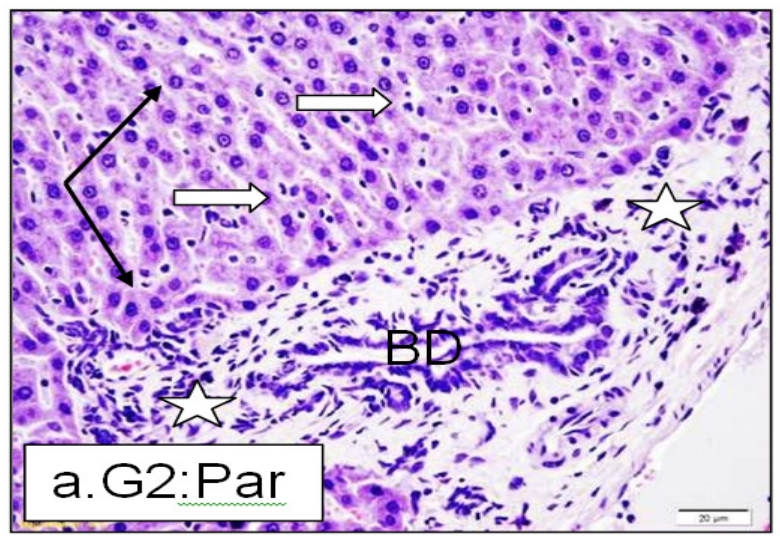

dark degenerated nuclei (black arrows). Blood sinusoids are slightly dilated and showed mononuclear cell infiltrate (white arrows). Portal region showed expansion, fibrosis and inflammatory cell infiltrate (stars) with signs of Bile Duct proliferations (BD), marked congestion of Portal Vein (PV) blood sinusoids (White arrows) and thickened Hepatic Artery (HA) and PV walls (thin black arrows) (Figure 6). Liver sections from rats pre-treated with captopril $20 \mathrm{mg} / \mathrm{kg}$ for 10 days (G3) showing slight or no changes in portal area, hepatocytes also looked normal (arrows) (Figure 7). The liver sections from rats pretreated with captopril $20 \mathrm{mg} / \mathrm{kg}$ and paracetamol 300 $\mathrm{mg} / \mathrm{kg}$ concomitantly for 10 days (G4) showed marked protection from paracetamol induced histological changes. Both portal elements and hepatocytes (arrows) looked more healthy than normal (Figure 8).

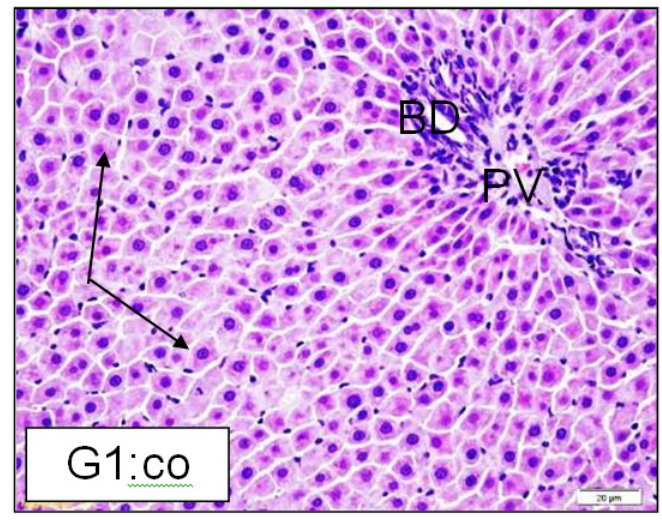

Figure 5. Normal control group: sections from rat liver (portal region) stained by H\&E.

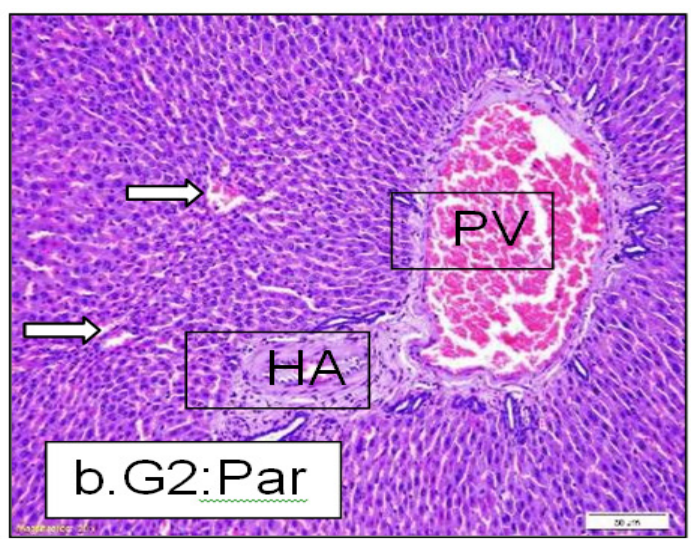

Figure 6. Paracetamol $300 \mathrm{mg} / \mathrm{kg}$ group: sections from rat liver (portal region) stained by H\&E. 


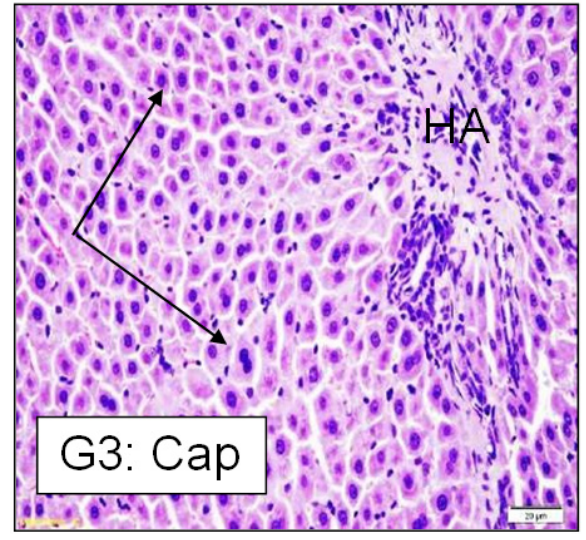

Figure 7. Captopril $20 \mathrm{mg} / \mathrm{kg}$ group: sections from rat liver (portal region) stained by H\&E.

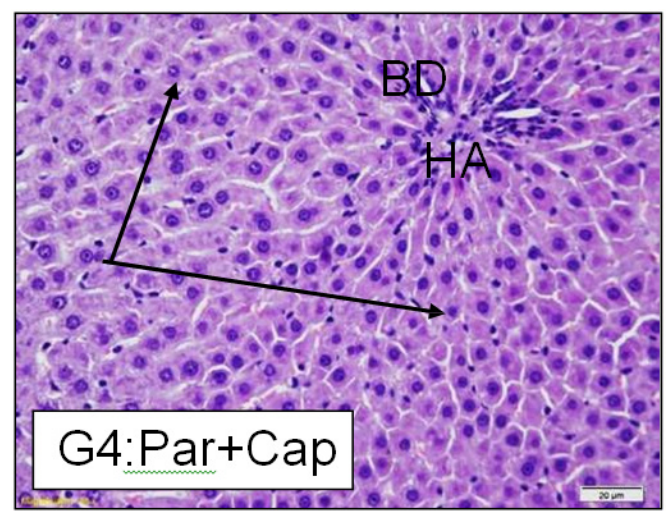

Figure 8. Captopril $20 \mathrm{mg} / \mathrm{kg}+$ Paracetamol $300 \mathrm{mg} / \mathrm{kg}$ group: sections from rat liver (portal region) stained by $\mathrm{H} \& \mathrm{E}$.

\subsection{Histological Findings of the Liver (High Dose Paracetamol and Captopril)}

Sections from rat liver stained by H\&E showed the liver sections from normal control group (group 1) administered normal saline with normal Central Vein
(CV) and hepatocyte cell cords (thin black arrows) separated by thin non-congested sinusoids (white arrows) (Figure 9). The histopathological examination of the liver tissues of rats pre-treated with paracetamol $3000 \mathrm{mg} / \mathrm{kg}$ single dose (group 2) showing marked perivascular (CV) degeneration and necrosis (squares in inset). Complete loss of hepatocyte outlines (star) compared to nonaffected cells (black arrows) was noticed [Figure 10 (a)]. Marked necrosis of hepatocytes (arrows) and damage of bile ducts (thick black arrows) with inflammatory cell infiltrate (white stars and inset) was also observed [Figure $10(\mathrm{~b})]$.

Liver sections from rats treated with captopril 20 $\mathrm{mg} / \mathrm{kg}$ (group 3) showing normal Central Vein (CV), hepatocytes cell cords (black arrows) and sinusoids (white arrows) (Figure 11). On the other hand the liver sections from rats treated with captopril $20 \mathrm{mg} / \mathrm{kg}$ and paracetamol $3000 \mathrm{mg} / \mathrm{kg}$ (group 4) showed that the hepatocytes looked normal without any signs of degeneration or necrosis (black arrows). Congestion in some Central Veins (CV) but Sinusoids are thin wall and non-congested (Figure 12).

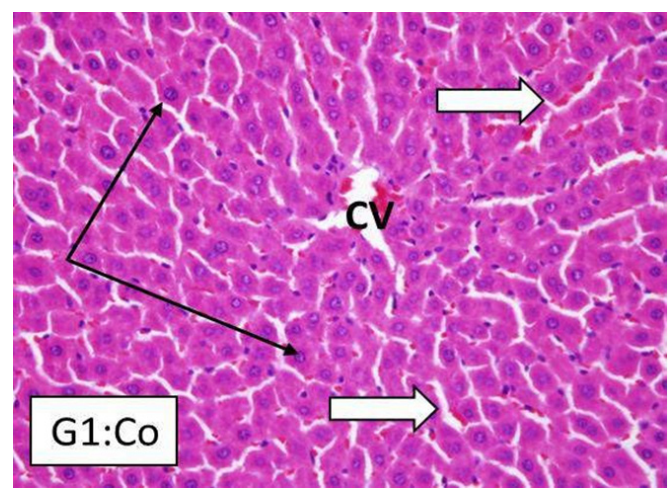

Figure 9. Normal control group: sections from rat liver stained by $\mathrm{H} \& \mathrm{E}$.

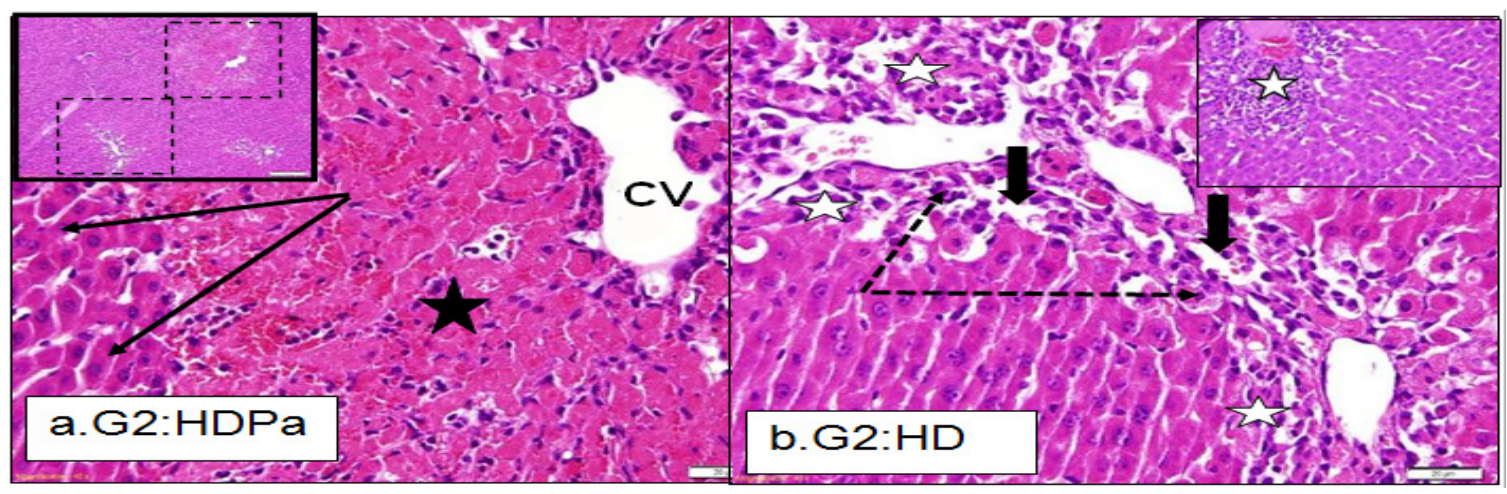

Figure 10. Paracetamol $3000 \mathrm{mg} / \mathrm{kg}$ group: sections from rat liver stained by H\&E. 


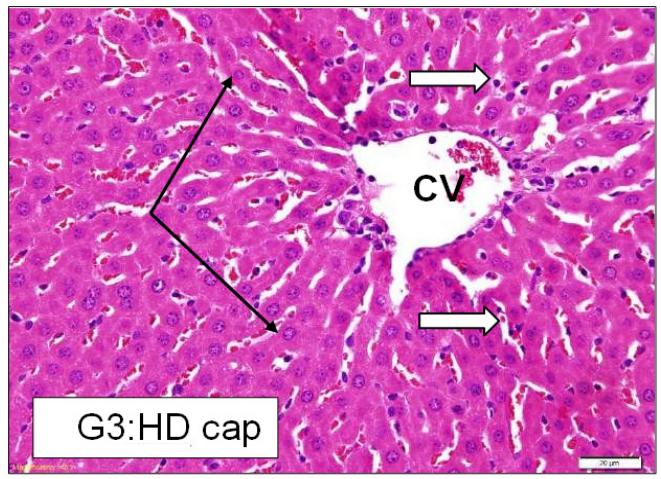

Figure 11. Captopril $20 \mathrm{mg} / \mathrm{kg}$ group: sections from rat liver stained by $\mathrm{H} \& \mathrm{E}$.

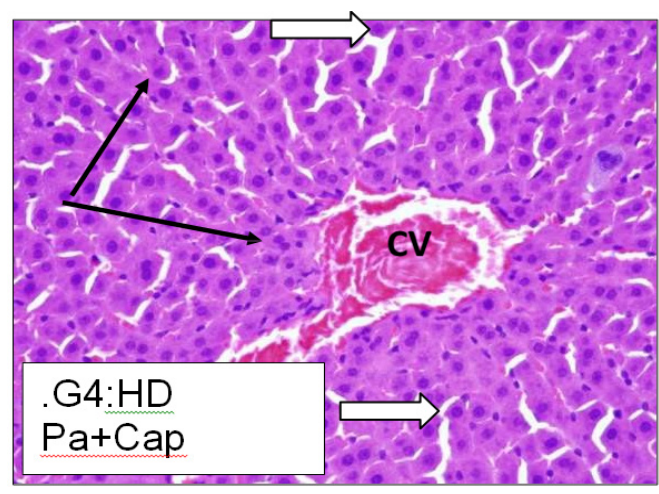

Figure 12. Captopril $20 \mathrm{mg} / \mathrm{kg}+$ Paracetamol 3000 $\mathrm{mg} / \mathrm{kg}$ group: sections from rat liver stained by H\&E.

\subsubsection{Portal Region}

As shown in the figures sections from portal region showed branches of Bile Duct (BD) and Portal Vein (PV) of control group (group 1) with normal appearance, no dilation or congestion, hepatocytes looked normal (arrows) (Figure 13). The histopathological examination of the liver tissue of rats treated with paracetamol 3000 $\mathrm{mg} / \mathrm{kg}$ (group 2) showed dilation and congestion of Portal Vein (PV) and Bile Duct proliferation (BD) and slight perivascular fibrosis (star) (Figure 14). Liver sections from rat treated with captopril $20 \mathrm{mg} / \mathrm{kg}$ (group 3) showing slight congestion of Portal Vein (PV) normal Bile Duct (BD) and hepatocytes (arrows) (Figure 15). While the liver sections from rats pre-treated with captopril 20 $\mathrm{mg} / \mathrm{kg}$ and paracetamol $3000 \mathrm{mg} / \mathrm{kg}$; showing marked protection with normal3 portal triad Portal vein (PV) slightly congested. Hepatic Artery (HA) and Bile Duct
(BD). Hepatocytes showed normal cytoplasm and vesicular active nuclei (arrows). Hepatic sinusoids are non-congested (Figure 16).

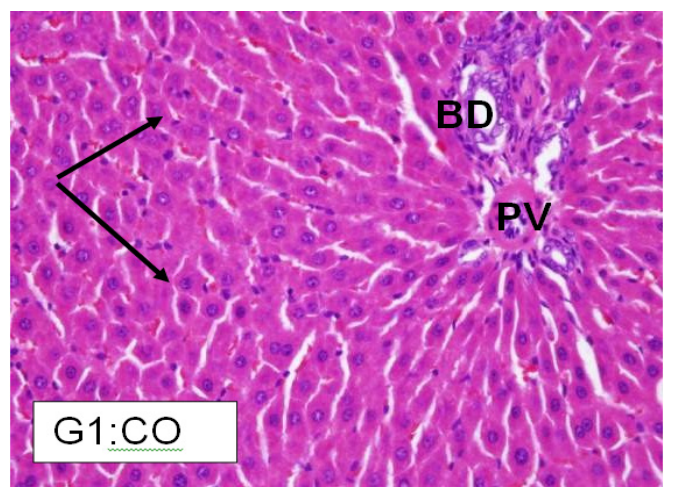

Figure 13. Normal control group: sections from rat liver (portal region) stained by H\&E.

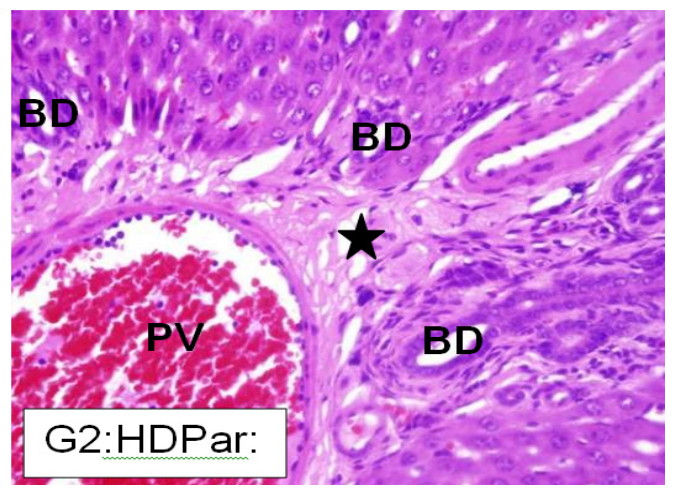

Figure 14. Paracetamol $3000 \mathrm{mg} / \mathrm{kg}$ group: sections from rat liver (portal region) stained by H\&E.

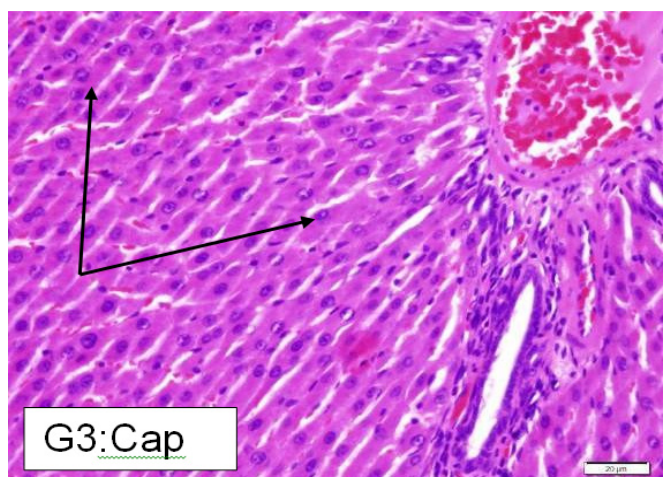

Figure 15. Captopril $20 \mathrm{mg} / \mathrm{kg}$ group: sections from rat liver (portal region) stained by $\mathrm{H} \& \mathrm{E}$. 


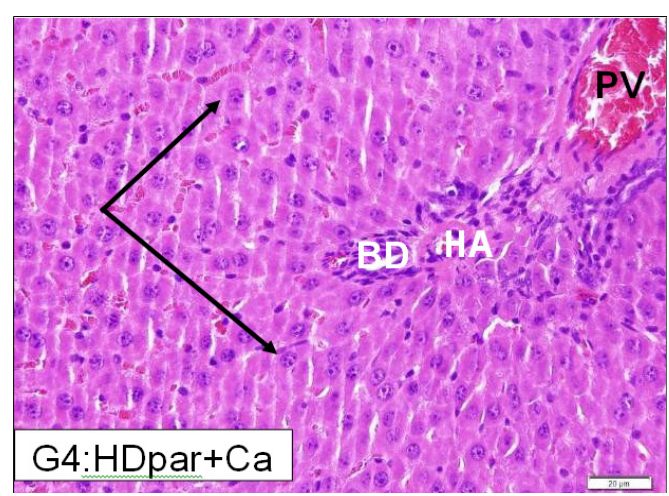

Figure 16. Captopril $20 \mathrm{mg} / \mathrm{kg}+$ Paracetamol 3000 $\mathrm{mg} / \mathrm{kg}$ group: sections from rat liver (portal region) stained by $H \& E$.

\section{Discussion}

Adverse drug reactions are considered serious problems worldwide. It is also known that many drugs and toxins can cause hepatotoxicity. Paracetamol is an over the counter drug that is reported to cause hepatotoxicity if taken in overdose $^{14}$. Paracetamol is metabolized by cytochrome $\mathrm{P}-450$ to $\mathrm{N}$-acetyl-p-benzo-quinoneimine (NAPQI). The NAPQI causes oxidative stress and glutathione depletion in liver cells which leads to hepatotoxicity ${ }^{16,17}$. Captopril is a well-known Angiotensin Converting Enzyme (ACE) inhibitor which is considered to be safe with no serious side effects. It is generally recommended for the treatment of hypertension, congestive heart failure, acute myocardial infarction and renal complications of diabetes mellitus ${ }^{18}$. In one of the previous studies captopril is reported to enhance total glutathione content as well as glutathione peroxidase and glutathione reductase activities in various mouse tissues ${ }^{12}$. However, according to another study captopril decreased the activity of both glutathione peroxidase and glutathione reductase ${ }^{13}$ Therefore, it was decided to evaluate the histopathological effects of captopril using paracetamol induced toxicity model $^{14}$.

In the present study, when paracetamol was administered to rats in low dose of $300 \mathrm{mg} / \mathrm{kg}$ for 10 days and a high single dose of $3000 \mathrm{mg} / \mathrm{kg}$, it produced hepatotoxicity as shown in Figure 2 and Figure 10, respectively. When captopril $20 \mathrm{mg} / \mathrm{kg}$ was administered with a low dose of paracetamol $300 \mathrm{mg} / \mathrm{kg}$ to rats for 10 days, it showed marked hepatoprotective effect (Figure 4). Furthermore, when a dose of captopril $20 \mathrm{mg} / \mathrm{kg} /$ day administered to rats for seven days was followed by a single dose of paracetamol $3000 \mathrm{mg} / \mathrm{kg}$, paracetamol induced hepatotoxicity was not observed (Figure 12 and 16).

These results indicate that captopril has hepatoprotective effects when evaluated through paracetamol induced toxicity model ${ }^{14}$. This result is in line with the study of Elena et al. $^{12}$ and Nora ${ }^{19}$, however, this result is contradicting the study of Habior ${ }^{10}$ and Ackerman et al ${ }^{13}$.

The authors believe that the hepatoprotective effect of captopril is because of its sulfhydryl (- $\mathrm{SH})$ group which is present in its chemical structure. This group acts as a scavenger of oxygen derived free radicals as has been reported by Ercument et $\mathrm{al}^{20}$.

\section{Conclusion}

In conclusion, from the present study it is evident that captopril exerts its hepatoprotective effect in paracetamol induced hepatotoxicity model. However to strengthen our findings it is recommended to study the hepatoprotective effect of captopril using different models.

\section{Acknowledgement}

The authors would like to thank faculty of pharmacy at the Northern Border University, KSA.

\section{Conflict of Interest}

None to declare.

\section{References}

1. Hussain T, Javed I, Khan FH, Muhammad F, Ahmad AB, Jan IU, Basit A, Tahir U. Effect of paracetamol on the renal clearance and urinary excretion of isoniazid in goats. Pakistan Veterinary Journal. 2009; 29(3):121-4.

2. Majee S, Ramadhan M, Monther W. Long-term toxicological effects of paracetamol in rats. Iraqi Journal of Veterinary Sciences. 2013; 27(1):65-70.

3. Mohammed AA, Hassan IA, Fahad A. Almulhim parac- 
etamol overdose: Analysis of a sample from a tertiary hospital in Eastern Saudi Arabia. Saudi Journal of Medicine and Medical Sciences. 2015; 3(3):209-12.

4. Chun LJ, Tong MJ, Busuttil RW, Hiatt JR. Acetaminophen hepatotoxicity and acute liver failure. J Clin gastroenterol. 2009; 43(4):342-9.

5. Lawson GR, Craft AW, Jackson RH. Changing patterns of poisoning in children in Newcastle. British Medical Journal. 1983; 37:291-5.

6. Walton WW. An evaluation of the Poisoning Prevention Packaging Act. Paediatrics. 1982; 69(3):363-70.

7. Robert PM, Bing L, Andrew F, Abdel Aziz M Sh, Hude Q. Hospitalizations for acetaminophen overdose: A Canadian population-based study from 1995 to 2004. BMC Public Health. 2007; 7:143.

8. Loh C, Ponampalam R. Nephrotoxicity associated with acute paracetamol overdose: a case report and review of the literature. Hong Kong Journal. 2006; 13(2):105-10.

9. Mohamed HA, Richard J, Balment, Nick A. Renal action of acute chloroquine and paracetamol administration in the anesthetized, fluid-balanced rat. The Journal of Pharmacology and Experimental Therapeutics. 2003; 306:478-83.

10. Habior A. Effect of captopril on glutathione level in the liver and paracetamol-A. Induced liver damage in rats. Pol Arch Med Wewn. 1992; 87(6):332-40.

11. Anton CS, Domenic AS, Barbara JB, Christopher SW. Renal considerations in angiotensin converting enzyme inhibitor therapy. Circulation. 2001; 104:1985-91.

12. Elena MVDC, Felipe I, Leon F, Cesar GF. Enalapril and captopril enhance glutathione-dependent antioxidant defenses in mouse tissues. American Journal of Physiology-Regulatory, Integrative and Comparative Physiology. 2000; 278(3):R572-7.
13. Ackerman Z, Oron-Herman M, Rosenthal T, Pappo O, Link G, Sela BA, Grozoyski M. Effect of captopril, and bezafibrate on oxidative milieu in rats with fatty live. Dig Dis Sci. 2008; 53(3):777-84.

14. Mahmood ND, Mamat SS, Kamisan FH, Yahya F, Kamarolzaman MFF, Nasir N, Mohtarrudin N, Md Tohid SF, Zakaria ZA. Amelioration of paracetamol-induced hepatotoxicity in rat by the administration of methanol extract of Muntingia calabura L. Leaves. BioMed Research International. 2014; 2014:695678.

15. Zakaria ZA, Rofiee MS, Somchit MN, Zuraini A, Sulaiman MR, Teh LK, Salleh MZ, Long K. Hepatoprotective activity of dried and fermented-processed virgin coconut oil. Evidence-Based Complementary and Alternative Medicine. 2011; 2011:142739.

16. Hemamalini K, Ramya K, Anurag B, Uma V. Hepatoprotective activity of Tabebuia rosea and Solanum pubescens against paracetamol induced hepatotoxicity in rats. Asian Journal of Pharmaceutical and Clinical Research. 2012; 5(4):153-6.

17. Blantz RC. Acetaminophen: acute and chronic effects on renal function. Am J Kidney Dis. 1996 Jul; 28(1):53-6.

18. Mesbah F, Soroush G, Sahar G. Protective effect of captopril on cisplatin induced hepatotoxicity in rat. American-Eurasian Journal of Toxicological Sciences. 2012; 4(3):131-4.

19. Nora M. Protective effect of captopril against 5-Fluorouracil-induced hepato and nephrotoxicity in male albino rats. Journal of American Science. 2012; 8(2):680-5.

20. Ercument O, Mustafa C, Siret R, Fazil A, Yavuz T, Sami K, Asim O, Gokhan H, Levent A, Nazim A. Effects of angiotensin converting enzyme inhibitors in healthy rats and in rats with carbon tetrachloride-induced toxic hepatitis. Turk Journal of Med Sciences. 2000; 30:321-5. 